\title{
Barriers and Facilitators for Adoption of Online Teaching Learning Methods during Covid-19 Pandemic among Medical Faculties in a Medical College of West Bengal - Qualitative Analysis
}

\author{
Manish Roy ${ }^{1}$, Bonapart Chowdhury², Riya Mondal ${ }^{3}$ \\ ${ }^{1}$ Department of Psychiatry, Shri Ramkrishna Institute of Medical Sciences and Sanaka Hospitals, Durgapur, West \\ Bengal, India. ${ }^{2}$ Department of ENT, Shri Ramkrishna Institute of Medical Sciences and Sanaka Hospitals, Durgapur, \\ West Bengal, India. ${ }^{3}$ Department of Community Medicine, Shri Ramkrishna Institute of Medical Sciences and Sanaka \\ Hospitals, Durgapur, West Bengal, India.
}

ABSTRACT

\section{BACKGROUND}

COVID- 19 pandemic hit the entire world and every institution was forced to close down. Medical education process comprises of theoretical classes, lab classes, practical classes as well as clinical classes. Medical institutes like other institutions were forced to start online teaching with fully knowing its limitation. Keeping in mind the recent new normal scenario, this study has been conducted in a medical college of West Bengal among medical faculties. We wanted to explore the barriers and facilitators for adoption of online teaching learning method among medical faculties in a medical college.

\section{METHODS}

This qualitative study was conducted among 24 medical educators of all disciplines of MBBS curriculum from 21 st August, 2020, to 30 th September, 2020. Data was collected by convenience sampling method. The subjects were interviewed with open ended questionnaire and data was analysed using Anthropac software. Free listing, pile sorting and thematic analysis was done.

\section{RESULTS}

Almost equal proportion of male (58.3\%) and female (41.7\%) faculties participated in this study. Lack of direct interaction, poor infrastructure, systematic error, problem in adapting teaching learning process were the main barriers while minimal contamination of COVID-19, uninterrupted teaching learning process were the facilitators of this process.

\section{CONCLUSIONS}

The coronavirus pandemic has raised huge difficulties for advanced education located around the world. A specific test has been the dire and surprising demand for already up close and personal college courses to be instructed on the web. On the web; instructing and learning suggest a specific academic substance information, principally identified with planning and arranging for better learning encounters and establishing unmistakable learning conditions, with the assistance of advanced innovations. Decoding and understanding these positives and negatives will help education system in creating strategies for more efficient delivery of the lessons, ensuring an uninterrupted learning journey for the students.

\section{KEY WORDS}

Qualitative Study, Free Listing, Pile Sorting, Thematic Analysis
Corresponding Author:

Dr. Riya Mondal,

Durgapur, West Bengal, India.

E-mail: riyamondal16@gmail.com

DOI: $10.14260 /$ jemds $/ 2021 / 798$

How to Cite This Article:

Roy M, Chowdhury B, Mondal R. Barriers and facilitators for adoption of online teaching learning methods during covid-19 pandemic among medical faculties in a medical college of West Bengal qualitative analysis. J Evolution Med Dent Sci 2021;10(45):3953-3957, DOI: $10.14260 / \mathrm{jemds} / 2021 / 798$

Submission 10-12-2021,

Peer Review 16-12-2021,

Acceptance 24-12-2021,

Published 28-12-2021.

Copyright (C) 2021 Manish Roy et al. This is an open access article distributed under Creative Commons Attribution License [Attribution 4.0 International (CC BY 4.0)] 


\section{BACKGROUND}

Medical education is a holistic approach that touches all domains of teaching like cognitive, affective and psychomotor. In 2019 new competent based medical education (CBME) has also given more emphasis on Socratic mode of communication i.e., two-way communication to make the curriculum more interactive. ${ }^{1}$ The new CBME erstwhile Medical Council of India has specified the teaching hours to be covered in lecture classes and in small group discussion. Our country with highest number of medical colleges in world, ${ }^{2}$ had started the new CBME curriculum since August, 2019. Then at its peak, pandemic COVID 19 hit the entire world. ${ }^{3}$ Every discipline was forced to close down their institution. After a brief period of time when it was evident that this pandemic will last for a long period all institutions took initiation and started online teaching with fully knowing its limitation. 4 Although cognitive domain might be covered by distance learning and online teaching, affective domain as well as psychomotor domain are quite hard to be taught in an online mode. Medical education process comprises of theoretical, lab, practical as well as clinical classes. ${ }^{5}$ Despite the obvious advantages of online and distance learning, there are certain problems that need to be considered. While technology is a key component of a distance learning program, it can also be one of the distance learning problems. One of the most frequently mentioned barriers is decreased live, face-to-face interaction between students and instructors. Instruction can be delayed or relayed poorly due to problems with multimedia equipment and Internet connections. Moreover, the technology and equipment required to participate in an online class might not be cheap. Other online and distance learning failures can be influenced by administration, instructional methods, or students. Online learners may encounter the lack of support and services such as providing tutors, knowledge of computers, and technical assistance. In many ways, each of these issues has an effect on the overall quality of online and distance learning. Some researchers point out that the effectiveness of online and distance learning does not depend on technology alone, but on the instructors' preparation also. Distance learning might result in poor outcomes if instructors do not design their online lessons properly. It is understandable that distance education does not work for everyone. It would not be a good idea for many people who are not self-directed or self-motivated and need to have interaction through the classroom. Teaching would be incomplete if all these avenues are not touched during the medical curriculum. Keeping in mind the recent new normal scenario, each and every medical teacher was forced to accustom with this new system of online medical education. ${ }^{6}$ Notwithstanding the conspicuous benefits of the web and distance learning, there are few issues that should be thought of. While innovation is a vital part of a distance learning program, it can likewise be one of the distance learning issues. Perhaps the most regularly referred barrier is diminished live and eye to eye association among understudies and educators. Guidance can be deferred or transferred ineffectively because of issues with media gear and web associations. In addition, the innovation and gear needed to take an interest in a web-based class probably won't be modest. On the web and distance learning disappointments can be affected by organization, informative strategies, or understudies. Online students might experience the absence of help like guides, information on PCs or other gadgets, and specialized help. In numerous ways, every one of these issues identifies with the others and affects the general nature of on the web and distance learning. A few scientists call attention to that the viability of on the web and distance learning doesn't rely upon innovation itself, yet on the teachers' arrangement. Distance learning may bring about helpless results assuming educators don't plan their internet based examples appropriately. Distance education system doesn't work for everyone: it would not be smart for some individuals who are not self-guided or self-inspired and need to have association through the lecture theatre. Thus, this study has been conducted to explore the facilitators and barriers of online teaching of medical undergraduates in this new normal considering the perspective and feedback from both the students and teachers.

\section{METHODS}

This qualitative study was conducted among 24 medical educators of all disciplines of MBBS curriculum of a Medical College, in Durgapur from 21st August, 2020 to $30^{\text {th }}$ September, 2020. Data was collected from 26-27th August, 2020 by convenience sampling method. The approach was made only after obtaining permission from the institutional ethics committee. [Letter reference no. SRIMSSH/IEC/20(02)/04]. Written consent was taken from each participant after explaining the whole procedure. Key informant interview was conducted among the faculties of different discipline about the facilitator and barriers of conducting online medical education. Responses of the teachers were taken against two specific questions, "What are the different barriers and facilitators for conducting online classes?" Respected teachers were asked to enlist their answer in their own words or simple phrase. We found that there were lots of barriers while facilitating factors are very few. So thematic analysis ${ }^{7}$ was adopted to create domain for facilitating factors and to enlist the barriers of online classes and to identify the cognitive domains of the problems, the method of free listing and pile sorting was done.8,9

Preferences of the enlisted problems were decided on the basis of Smith's Salience Index. ${ }^{10}$ Free list is a form of accumulation of data of participant's words or phrases which are analysed according to the repetitiveness of the similar words or phrases. Variation in emic perspective, exploration of important or salience points can be obtained from free list. Relevance of the items is decided on the basis of cut-off point. This cut-off point is decided upon the salience point of Smith below which there is a drastic drop in rest of the values. Pile sorting is qualitative technique which helps in identifying the different domains of items. Individual participants are generally asked to enlist the similar items into same group and make different groups of the items. In this current study salience items which were obtained from free list, were written in different cards. One to-one exercise was done among 6 willing teachers where they were asked to separate the cards of problems and make piles of similar problems according to their understanding. Piles were made as pile1, pile2, pile3. 


\section{Statistical Analysis}

Data was entered in Notepad following specific command and analysed in Visual Anthropac version 1.0 software.

\section{RESULTS}

Almost equal proportion of male (58.3\%) and female (41.7\%) faculties participated in our study among whom $66.7 \%$ belonged to the age group of 24 to 50 years.

\section{Barriers of Conducting Online Classes}

Problems of conducting online classes were enlisted and priorities by free listing (Table no. 1). Depending on Smith's Salience Index, 10 items were selected for pile sorting considering 0.045 as the cut-off marks.

Those were lack of interaction, unable to look after students, poor internet connection, difficulties in demonstration, difficulties in assessment, students lack interest, inadequate infrastructure, inappropriate technical support, difficulty in getting feedback from students, lack of expertise.
Those ten problems were organized under four separate categories by pile shorting. These categories are as follows-

- $\quad$ Lack of direct interaction -

- Poor infrastructure,

- Systematic error,

- Problem in adapting teaching learning process.

\begin{tabular}{|cccc|}
\hline Items & Frequency & $\begin{array}{c}\text { Average } \\
\text { Rank }\end{array}$ & Salience \\
\hline Poor internet connection & 75 & 1.6 & 0.627 \\
Lack of interaction & 54 & 1.6 & 0.453 \\
Difficulties in demonstration & 50 & 3.0 & 0.280 \\
Unable to look after students & 50 & 1.9 & 0.384 \\
Difficulties in assessment & 33.3 & 3.9 & 0.116 \\
Inadequate infrastructure & 20.8 & 3.4 & 0.088 \\
Students lacks interest & 16.7 & 3.3 & 0.076 \\
Inappropriate technical support & 12.5 & 2.7 & 0.078 \\
Difficulty in getting feedback from students & 12.5 & 4.0 & 0.060 \\
Lack of expertise & 8.3 & 2.5 & 0.045 \\
No patient student interaction & 4.2 & 6.0 & 0.012 \\
No case base discussion & 4.2 & 7.0 & 0.006 \\
Non-compliance of students & 4.2 & 1.0 & 0.002 \\
Student cannot connect on time & 4.2 & 4.0 & 0.010 \\
Unnecessary time waste & 4.2 & 2.0 & 0.021 \\
Chalk and talk is not possible & 4.2 & 5.0 & 0.008 \\
Chance of getting infection from keyboard & 4.2 & 4.0 & 0.010 \\
Active eye contact is lacking & 4.2 & 4.0 & 0.010 \\
Monotonous & 4.2 & 5.0 & 0.018 \\
Many students don't have good net connection & 4.2 & 7.0 & 0.006 \\
Group task is difficult & 4.2 & 1.0 & 0.012 \\
Less attendance & 4.2 & 3.0 & 0.025 \\
\hline Table 1. List of Problems of Conducting Online Classes \\
\hline
\end{tabular}

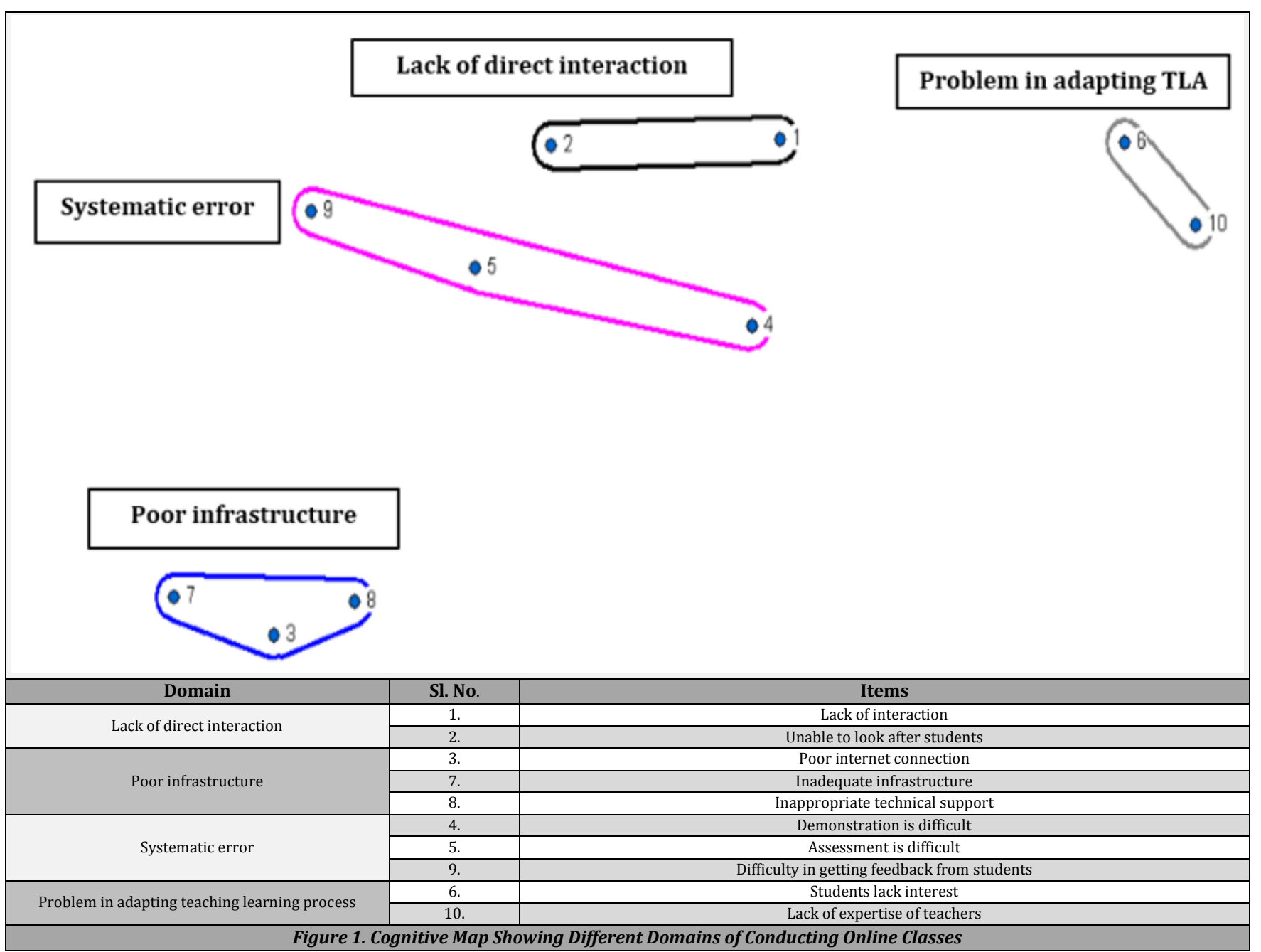

After pile shorting, four separate domains has been recognized- lack of direct interaction, poor infrastructure, systematic error, problem in adapting teaching learning process. 


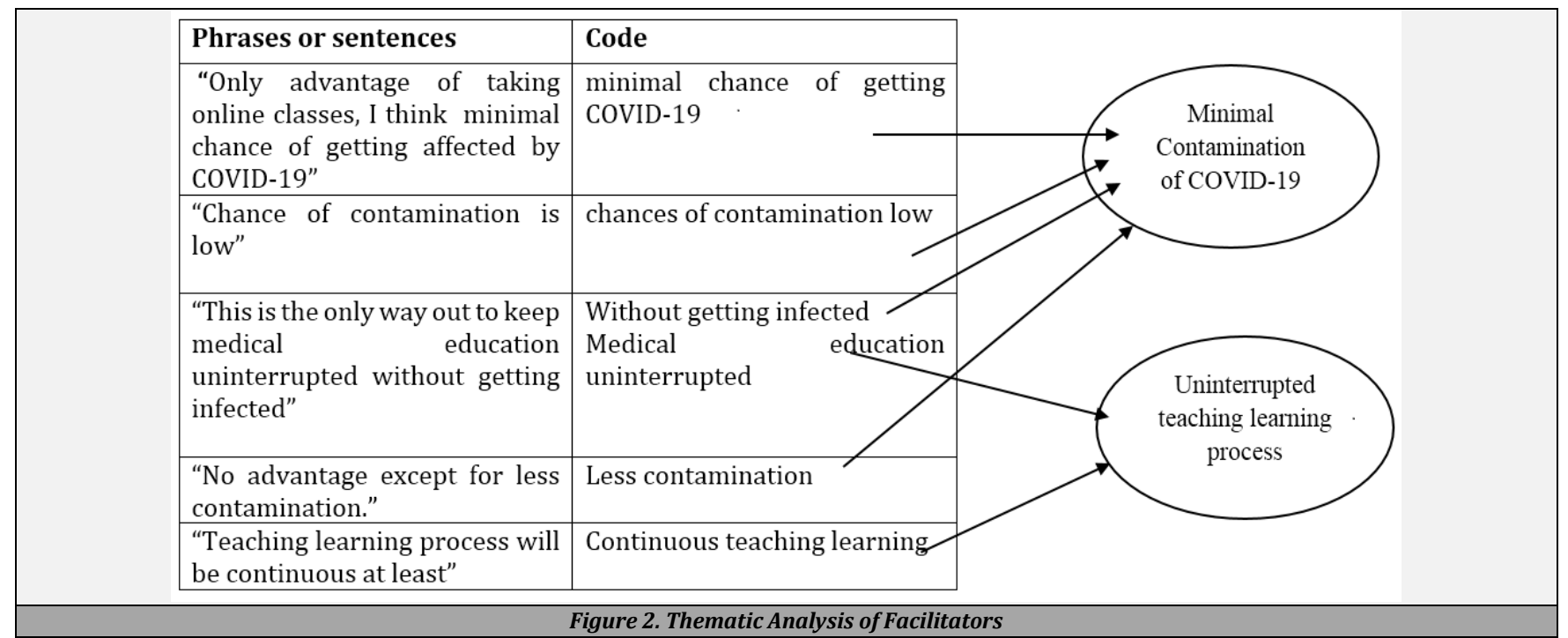

There were very few responses about the facilitators of online classes. Answers were coded and organized to be reflected as themes. Two themes were identified from codes- minimal contamination of COVID 19 and uninterrupted teaching learning process.

So, Force field analyses of online classes reflected there were barriers of conducting online classes. Barriers like lack of interaction, poor infrastructure for internet, lots of systematic errors, difficulties in adopting teaching learning method and many more but during COVID-19 it is the only way where teaching could be continued without interruption and with minimal contamination of Corona virus.

\begin{tabular}{|c|c|c|}
\hline \begin{tabular}{l}
\multicolumn{1}{c}{ Barriers } \\
- Lack of direct interaction \\
- Poor infrastructure \\
- $\quad$ Systematic error \\
- $\quad$ Problem in adopting teaching \\
$\quad$ learning assessment
\end{tabular} & $\begin{array}{l}\text { Online } \\
\text { classes }\end{array}$ & \begin{tabular}{l}
\multicolumn{1}{c}{ Facilitators } \\
- Minimal contamination of \\
COVID-19. \\
- Uninterrupted teaching \\
learning process
\end{tabular} \\
\hline
\end{tabular}

\section{DISCUSSION}

One of the most oft-used terms after the pandemic is the term "new normal." The new normal in education is the increased use of online learning tools. The COVID-19 pandemic has triggered new ways of learning. All around the world, educational institutions and faculties of different discipline are looking toward online learning platforms to continue with the process of educating students. In several studies 3,4 we have seen that most teaching methods, online learning also has its own set of positives and negatives. Decoding and understanding these positives and negatives will help education system in creating strategies for more efficient delivery of the lessons, ensuring an uninterrupted learning journey for the students. Like the article The Versatility and Effectiveness of Online Learning, ${ }^{5}$ we have found that the barriers are skewed heavily than the facilitators for online learning. The barriers are-
1) Poor infrastructure but it can be minimized by use of renewable energy, e.g., solar power and electric generators, strengthening Internet bandwidth, universal access of intranet, extension of computer laboratories and providing equipment like Govt. subsidized tablets or mobile phones, creation of regional online centres to increase education access.

2) Problems of adaptation to new system of teaching learning assessment by the teachers which can be reduced by educating the teachers through trainings, authoritative policy and by providing incentive to the teachers for financial motivation to adopt a new system of education delivery.

3) Lack of direct interaction which, however remains the biggest challenge to have a solution because whatever might be the advancement of technologies till now, actual in person human interaction cannot be achieved, which seems to be a crucial barrier in providing online education as it is an important attribute to psycho- 
cognitive domain of concepts and education delivery system but with the technological advancement of augmented and virtual realities this seems to be not a far-fetched idea but this will take time to be available and usable technology for the general population and definitely same is applicable for the medical teachers.

4) Systemic errors like difficulty in demonstration, assessment and difficulty in getting feedback from students are present. But unfortunately, it is unavoidable especially for the practical and clinical teaching which are of paramount importance for a medical student, however, dummy patients like actors mimicking the classical signs and symptoms of a disease can be demonstrated in online classes, but it will hardly be as good as examining and managing a real patient in real life scenario. Difficulty in assessment can also be addressed by, though not full proof, mandating the students to keep on their front camera of the gadgets they are using during the assessment to avoid any elusive methods used by the students.

Like the studies of Mishra L et al. ${ }^{6}$ this study also has barriers of online education, but considering the current Covid-19 pandemic scenario where nothing should be more important than protecting a precious human life from this deadly virus by adopting the WHO guideline for Covid appropriate behaviour, the online method of education delivery system is 'the' ray of hope to facilitate breaking the chain of contamination and also to continue the uninterrupted teaching learning method in medical education.

\section{Limitations}

This study included only one medical college in the state of West Bengal, India, by using a key person analysis method, which restricts the generalizability of the outcomes. Nonetheless, the survey had high inward dependability as subscales with questions gathered by theorized factors were summed up. Indeed, even still, the reaction rate might have presented a choice or non-reaction predisposition by getting information from one organization and, conceivably, of workforce with solid feelings corresponding to online training. The entrance or constraints of distance-learning assets of this college might have likewise affected the view of hindrances to web-based educating by the members participating the key person interview. Regardless of these impediments, the discoveries from this study are viable.

\section{CONCLUSIONS}

Though online climate just as given admittance to training to students who might not have the option to go to courses at college grounds. In spite of the fact that utilization of provincial focuses apparently was a dependable procedure especially in disconnected conditions, they had a few constraints with regards to Internet openness. At the point when Internet was free, then, at that point, the speed would be astoundingly sluggish. This review recommends that Internet transfer speed limit was as yet a limitation for a fruitful e-learning in such focuses just as their host organizations.

This review has tried to reveal insight into the hindrances of online class's appropriations in clinical schools and procedures that can be utilized to address them. In the first place, it is obvious that until to date infrastructural issues, especially power supply, data transmission limit, PC labs including PCs, are as yet connected with hindrances of online classes reception. Notwithstanding, proof from these foundation shows that there were a few measures taken to address these obstructions including sun-oriented power frameworks, improvement of Web network, and development of new structures and foundation of provincial focuses.

Data sharing statement provided by the authors is available with the full text of this article at jemds.com.

Financial or other competing interests: None.

Disclosure forms provided by the authors are available with the full text of this article at jemds.com.

\section{REFERENCES}

[1] Basheer A. Competency-based medical education in India: Are we ready.J Curr Res Sci Med 2019;5:1-3

[2] Mitra J, Saha I. Attitude and communication module in medical curriculum: rationality and challenges. Indian J Public Health 2016;60(2):95-8.

[3] Liu YC, Kuo RL, Shih SR. COVID-19: The first documented coronavirus pandemic in history. Biomed J 2020;43(4):328-33.

[4] Mathivanan SK, Jayagopal P, Ahmed S, et al. Adoption of Online classes during Lockdown in India. Int J Syst Assur Eng Manag 2021. https://link.springer.com/article/10.1007\%2Fs13198021-01072-4 .

[5] The Versatility and Effectiveness of Online Learning [Internet]. [cited 2021 Jun 18]. Available from: https://www.onlinestudies.com/article/the-versatilityand-effectiveness-of-onlinonline classes/

[6] Mishra L, Gupta T, Shree A. Online teaching-learning in higher education during lockdown period of COVID-19 pandemic. Int J Educ Res Open 2020;1:100012.

[7] Castleberrya A, Nolenb A. Thematic analysis of qualitative research data: is it as easy as it sounds? Science Currents in Pharmacy Teaching and Learning 2018;10(6):807-15.

[8] Quinlan MB. The freelisting method. In: Liamputtong P, ed. Handbook of research methods in health social sciences [Internet]. Singapore: Springer 2017:1-16.

[9] Yeh HW, Gajewski BJ, Perdue DG, et al. Sorting it out: pile sorting as a mixed methodology for exploring barriers to cancer screening. Qual Quant 2014;48(5):2569-87.

[10] Analytic Technologies. Available from: http://www.analytictech.com/anthropac/anthropac.ht $\mathrm{m}$ 